\title{
The drift of early life stages of Percidae and Gobiidae (Pisces: Teleostei) in a free-flowing section of the Austrian Danube
}

\author{
D. Ramler • H. Ahnelt $\cdot$ H. L. Nemeschkal • \\ H. Keckeis
}

Received: 17 March 2016/Revised: 10 May 2016/Accepted: 26 May 2016/Published online: 7 June 2016

(C) The Author(s) 2016. This article is published with open access at Springerlink.com

\begin{abstract}
The drift of early development stages is an essential element of dispersal in many fish species. It is caused by a multitude of factors and is thus highly specific for each taxon and developmental stage. In this paper, we examined the drift of free embryos, larvae, and juveniles of percids and gobiids in a freeflowing stretch of the Austrian Danube. We assessed the drift density (DD) at different distances from the shore, described seasonal and diel patterns, and how size of drifting fish changed throughout the season. The seasonal patterns as well as the DDs were highly specific for each genus, while the diel patterns and changes in size of drifting fishes differed primarily at family level. In addition, we compared two opposed shorelines-a near-natural gravel bar and a rip-rap stabilized shore. The shores differed significantly and on both shores the DD of gobies was higher compared
\end{abstract}

Electronic supplementary material The online version of this article (doi:10.1007/s10750-016-2845-0) contains supplementary material, which is available to authorized users.

Handling editor: Alison King

D. Ramler $(\varangle) \cdot$ H. Keckeis

Department of Limnology and Bio-Oceanography,

University of Vienna, Althanstraße 14, 1090 Vienna,

Austria

e-mail: david.ramler@univie.ac.at

H. Ahnelt · H. L. Nemeschkal

Department of Theoretical Biology, University of Vienna,

Althanstraße 14, 1090 Vienna, Austria to percids. Among the Gobiidae, the invasive Neogobius species clearly dominated $(99 \%$ of total gobiid catch) over the native tubenose goby Proterorhinus semilunaris. Percid DD was substantially higher on the near-natural shore, with Zingel and Sander as the most abundant genera.

Keywords Rip-rap · Gravel bar · Large river · Seasonal pattern $\cdot$ Diel pattern $\cdot$ Shore morphology

\section{Introduction}

The downstream drift of early stages is a common and important life history event in many fish species. It is important for dispersal, as well as for reaching suitable nursery habitats after hatching (Pavlov et al., 1978; Brown \& Armstrong, 1985; Pavlov, 1994; Fuiman \& Werner, 2002). Drift entry of fish species is influenced by a number of abiotic and biotic factors, such as discharge, flow velocity, population density, predation, or foraging (Oesmann, 2003; Zitek et al., 2004a; Reichard \& Jurajda, 2007). The main factors of timing and intensity of drifting, however, are linked to spawning events, which in turn are primarily influenced by temperature in temperate rivers (Brown \& Armstrong, 1985; Reichard et al., 2002b). This leads to seasonal characteristics of drift activity of relatively limited duration (weeks-months) in most species inhabiting temperate zones (Zitek et al., 2004a; 
Reichard \& Jurajda, 2007). Furthermore, many species exhibit diurnal changes in drift activity, with fish drifting more commonly during the night (Pavlov et al., 2000; Reichard et al., 2002b; Zitek et al., 2004a; Nunn et al., 2010). Drifting itself (i.e. the mode of transport in the current) can be active or passive (or a combination of both), depending on the orientation of the fish and its swimming abilities (Pavlov, 1994). The drift of early life stages of fishes can therefore be considered a highly taxon- and stage-specific phenomenon (Zitek et al., 2004b; Reichard \& Jurajda, 2007), which is caused by a combination of passive and active components, governed by physical conditions, behaviour, and developmental processes (Pavlov et al., 2000; Freeman et al., 2001; Wolter \& Sukhodolov, 2008; Lechner et al., 2013).

Although the drift of early life stages is caused by a multitude of factors, and despite some of its aspects being still poorly understood (e.g. drift duration and distance), drift analyses are nevertheless able to provide very valuable information on the occurrence and reproduction of fishes within a river section. The occurrence of early life stages in the drift shows that (1) suitable spawning grounds exist and reproduction was successful, (2) conditions were suitable for the eggs to develop, and (3) adequate habitats were present, in which the young fish were able to feed and grow (see also Humphries \& Lake, 2000). In addition, due to the high specificity, drift analyses can also provide information on otherwise underrepresented taxa and ontogenetic stages.

Studies in the Danube and its tributaries revealed up to seven families which occur in the drift. However, only the Cyprinidae, Gobiidae, and Percidae are regularly caught in larger numbers, indicating that drifting plays a significant role in their life histories (Zitek et al., 2004b; Lechner et al., 2010, 2014). Drift patterns in cyprinids have been extensively described and discussed (Reichard et al., 2002a, 2004; Sonny et al., 2006; Reichard \& Jurajda, 2007), including the effect of shore morphology on cyprinid drift (Schludermann et al., 2012; Lechner et al., 2013). Much less is known about the drift characteristics of other families, especially on a low taxonomic scale. In addition, cyprinids are by far the most frequently encountered family in point abundance samples of inshore habitats of European rivers, whereas percids and gobiids are only rarely caught with this method (Copp, 1997; Janáč \& Jurajda, 2007; Keckeis, 2013).
As a consequence, knowledge about the early life stages of these families is scarce. The percids (eight species in the Austrian Danube) consist of native species, and most of them are considered endangered (Wolfram \& Mikschi, 2007). Many percids are habitat specialists, preferring either fast flowing or still waters, also for reproduction (Schiemer \& Waidbacher, 1992). The gobiids (four species in the Austrian Danube), in contrast, are generalists and are notorious for their invasiveness (Charlebois et al., 1997; Wiesner, 2005). Only one gobiid species, the Western tubenose goby Proterorhinus semilunaris, is regarded as native and endangered in Austria (Ahnelt, 1988; Wolfram \& Mikschi, 2007). Both families are therefore of high ecological importance.

Different shore types entail different suitabilities as spawning or nursery habitats for different taxa and also directly affect the drift due to differences in hydro-dynamic parameters, such as flow velocity and direction. Previous studies attempted to assess the effect of river hydro-morphology on drift patterns, by comparing different rivers (Pavlov et al., 1978; Scheidegger \& Bain, 1995; Reichard et al., 2001; Humphries et al., 2002), or different river sections (Freeman et al., 2001; Zitek et al., 2004b). Information on how different shore types within a river section have an influence on the drift is especially valuable, as the shores are thus under the same hydrological regime, which allows a direct comparison of drift activity (Oesmann, 2003; Lechner et al., 2013).

Shore morphology is particularly important for the early life stages of fishes, as they often exhibit complex habitat requirements and are thus very useful as indicators for the ecological status of a river (Schiemer et al., 1991). The occurrence, abundance, and composition of $0+$ fish assemblages provide insights about the existence and quality of key microhabitats (e.g. for spawning, hatching, or foraging) in a given river section (Schiemer et al., 1991; Wintersberger, 1996; Schiemer, 2000; Grift et al., 2003). This holds especially true for habitat specialists (as are many endangered species) and their specific requirements that have to be met (Schiemer, 2000), but vice versa also for eurytopic species (as are many invasive species), which may indicate modified or impoverished environmental conditions (Baltz \& Moyle, 1993; Alexander et al., 2015). Consequently, analysing the drift of $0+$ percids and gobiids is a 
functional and practical method to gather information about the presence of spawning and nursery habitats (i.e. start and end points of drifting), although it may not be possible to trace their exact location.

To this end, the main aim of the present study was to assess several drift characteristics of early stages of percids and gobiids in a straight, free-flowing section of the main stem of the Austrian Danube. These characteristics include taxonomic composition (down to genus level), seasonal and diel patterns, and size structure of drifting fishes. Given the different life history strategies of percids and gobiids (Balon, 1975, 1990; Penaz, 2001), we expect pronounced differences in drift patterns.

To provide more information of drift patterns within these families, the second aim of this study was to compare the drift along two different shore types. These were a stabilized shore (rip-rap) and, on the opposite side, a near-natural gravel bar. Percids and gobiids belong to different reproductive guilds and prefer different habitats as adults. We expect this preference to be reflected in the occurrence and abundance of early life stages which in turn will lead to differences in drift densities (DDs) between the shores, and, to a lesser extent, also of the other drift characteristics.

\section{Material and methods}

Study area

The study was conducted on two shores of the main channel of the Austrian Danube, between river kilometres 1,890.0 and 1,893.8, within the Danube Alluvial Zone National Park (Fig. 1). Although regulated, the Danube reach within the national park is one of the two last remaining free-flowing stretches in Austria (Schiemer \& Waidbacher, 1992). Within the sampling area, the right shore is straightened and stabilized by basalt blocks (rip-rap) and has a steep bank. Large groynes, perpendicular to the axis of the main channel, have been installed for navigation purposes. The left shore was once similar to the right shore but has been re-structured in 2007 to a shallowsloped gravel bar, accompanied by smaller groynes, with no connection to the shore (Fig. 2). For clarity and uniformity, the right shoreline is hereinafter referred to as 'stabilized' and the left as 'near-natural'.
The shores are situated opposite each other. A more detailed hydraulic characterization of the shores, as well as a detailed description of the sampling method, can be found in Lechner et al. (2013). Values for daily discharge of the Danube were obtained from the nearest hydrological station at Wildungsmauer (Fig. 3).

We assume that fish caught on one side of the river also hatched on the same side and were not able to cross the river because (1) fish larvae usually drift close to the bank (de Graaf et al., 1999; Reichard et al., 2004 and citations listed therein), (2) the river in this section meanders little (Pavlov et al., 2008), and (3) mixing of the river between the two shores is unlikely (Fischer, 1979).

\section{Sampling of early life stages of fish}

Sampling took place on 18 days between 9 May and 20 June 2011, with intervals from 1 to 7 days (Table 1). At four sampling stations at each shore, samples were taken with three conical drift nets $(0.5 \mathrm{~m}$ diameter, $1.5 \mathrm{~m}$ long, $500 \mu \mathrm{m}$ mesh), equipped with detachable collecting boxes. Nets were fixed by $2 \mathrm{~m}$ long ropes attached to metal stacks which had been driven into the ground, allowing the nets to follow the current (Humphries \& King, 2004). At each sampling site, the three nets were located at different distances from the bank (termed inshore IN, midshore MID, offshore OFF). Sampling sites were located at the groyne heads on the stabilized shore and along the bank on the near-natural shore. Due to the different shore morphologies and water levels, the distances between the nets and the shoreline varied from approximately 0.5 to $2 \mathrm{~m}$. All four net triplets (IN, MID, OFF) on a shore were simultaneously exposed and left in the flow for approximately $20 \mathrm{~min}$. The nets were deployed so that the upper rim of the net was just below the water surface, unless water depth was too low for this. Sampling took place in 1-h intervals, up to five times a day (from 19:00 to midnight; CEST), yielding a maximum of 60 samples (i.e. nets) per day and shore. A flow meter (2030R, General Oceanics, Miami, USA) was attached at the lower third of the entrance of each net to measure the volume of filtered water. All captured fish were anaesthetized and killed with an overdose of MS-222 (Tricaine methanesulfonate, Sigma-Aldrich, St. Louis, USA) and preserved in $96 \%$ ethanol. 


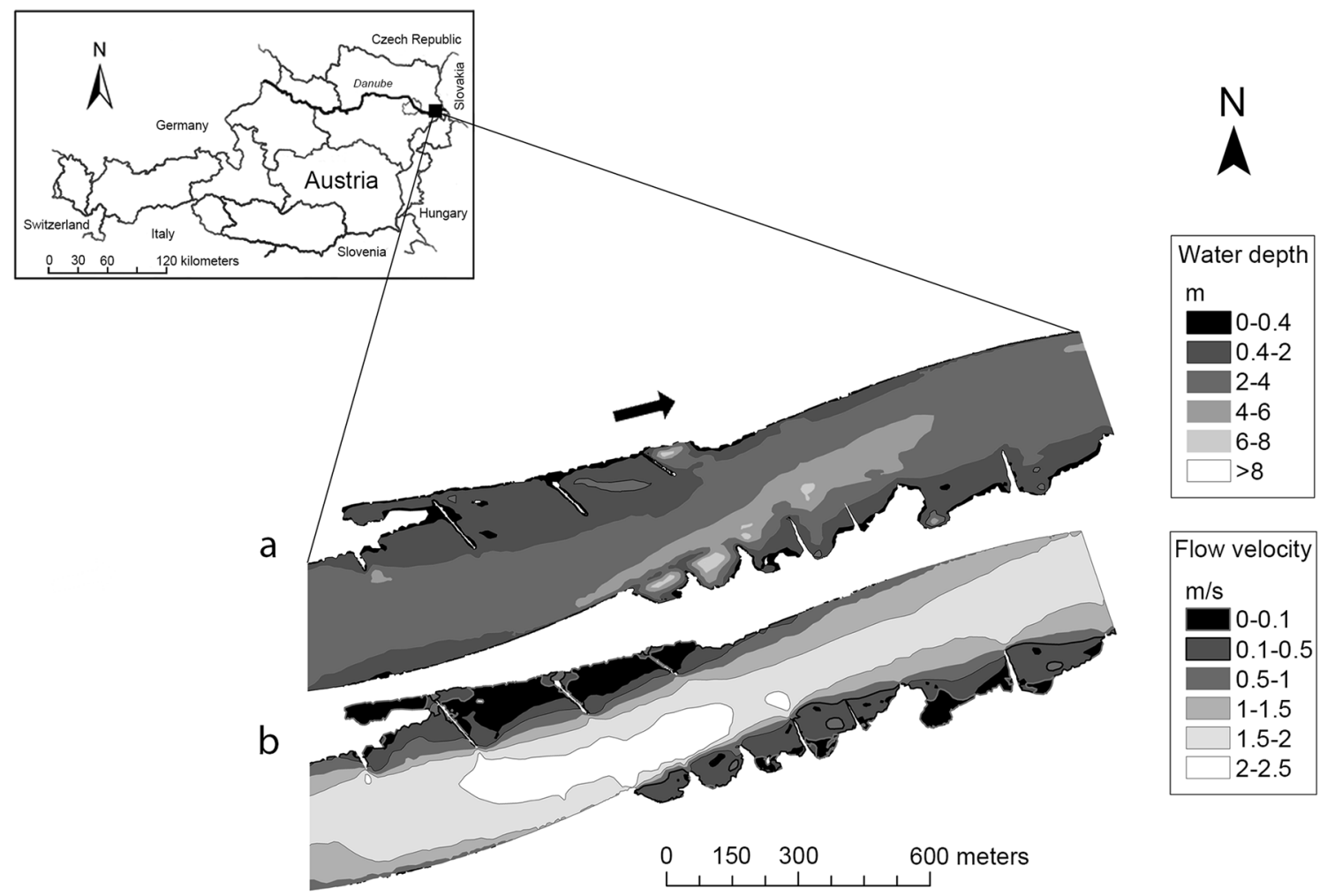

Fig. 1 Map of the study area with water depths (a) and flow velocities (b). The arrow indicates the direction of flow. Modified after Lechner et al. (2013)

Sample processing and identification

In the laboratory, the specimens were separated into taxonomic families and the early stages of the Gobiidae and Percidae where further identified to genus level. It is not possible to determine all early stages of percids and gobiids to species level without genetic tools. The identification of genera was accomplished using our own reference collection (see Ramler et al., 2014), general identification keys for young fishes (Koblickaya, 1981; Urho, 1996), as well as literature on early development (Mansueti, 1964; Kovac, 1994, 2000; Leslie et al., 2002; Leslie \& Timmins, 2004; Specziar et al., 2009).

The species of the Percidae and Gobiidae occurring in Austria are presented in Table 2. For better readability, we use only the genus name throughout the text (and in the figures), also when referring to species within a genus (i.e. 'Zingel' instead of 'Zingel spp.'), or monotypic genera (i.e. 'Perca' instead of 'Perca fluviatilis'). Nomenclature follows Kottelat \&
Freyhof (2007). The tubenose goby $P$. semilunaris and all percid species are native to the sampled section of the Danube (Ahnelt, 1988; Wolfram \& Mikschi, 2007). The three other gobiid species are listed as invasive (Ahnelt et al., 1998; Wiesner, 2005).

The total length (TL) of all fish was measured with an accuracy of $0.5 \mathrm{~mm}$ and was used as a proxy for development stage. If the number of larvae in a sample exceeded 35, then the subsamples of 30 individuals were taken randomly, and the identification and length measurement results were extrapolated for the whole sample.

\section{Data analysis}

Prior to the analysis, all samples were standardized by calculating DDs, which were specified as the number of individuals per $100 \mathrm{~m}^{3}$ of filtered water. The DD per shore and day (seasonal pattern) and sampling hour (diel pattern) were not normally distributed. The data were therefore normalized by the log- 


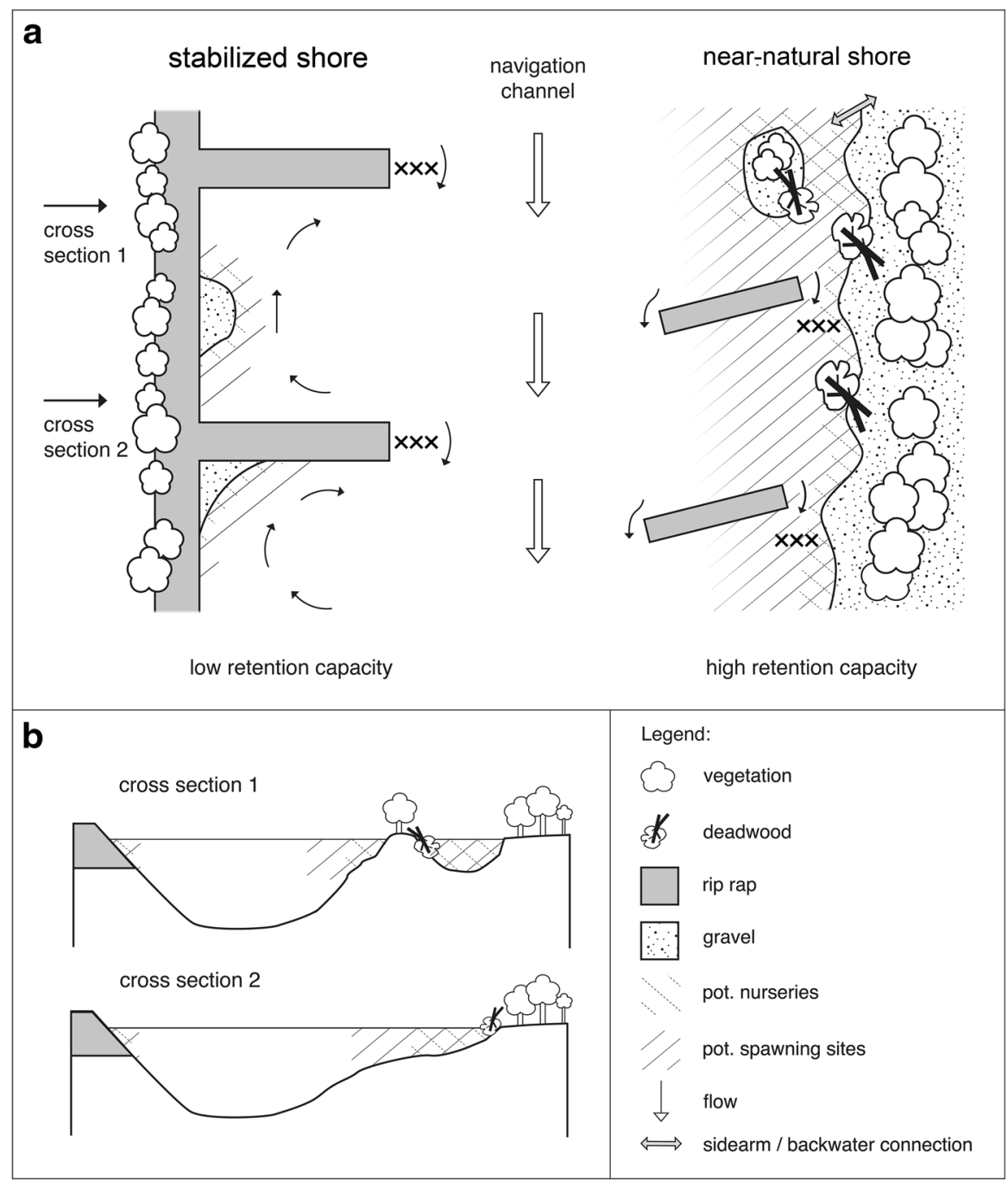

Fig. 2 Schematic overview illustrating differences between the two investigated shores. a Top view, arrows indicate flow directions, length and thickness of the arrows indicate strength

transformation $b=\log (x+d)-c$, where $x$ is the original DD, $d$ a decimal constant, and $c$ an order of magnitude constant (following McCune et al., 2002).

A linear discriminant analysis after the general linear model (GLM) was used to discern differences between the shores in gobiids and percids. To analyse spatial differences, we conducted an ANOVA after the GLM with DD as the criterion, sampling location, and distance from shore as factors, and sampling date and time as co-variates. The discriminant analysis and the ANOVA have been backed up by 10,000 bootstrap resamplings. For each genus, we used a $G$-test for of flow velocity, and crosses indicate the position of the net triplets. b Cross sections of the river at positions marked in a. Pot. potential

goodness-of-fit to compare the seasonal and diel patterns along each shore (Sokal \& Rohlf, 1995; Agresti \& Kateri, 2011). We regarded the course on one shore as the observed distribution and the other as the expected distribution, with the null hypothesis that both distributions do not differ. It should be noted that the sample sizes were low for Proterorhinus, Perca, and Gymnocephalus, which is why the results of the $G$-test should be interpreted with caution for these genera. To give insight into single or multiple spawning events, we assessed how size of drifting individuals changed throughout the sampling period, 


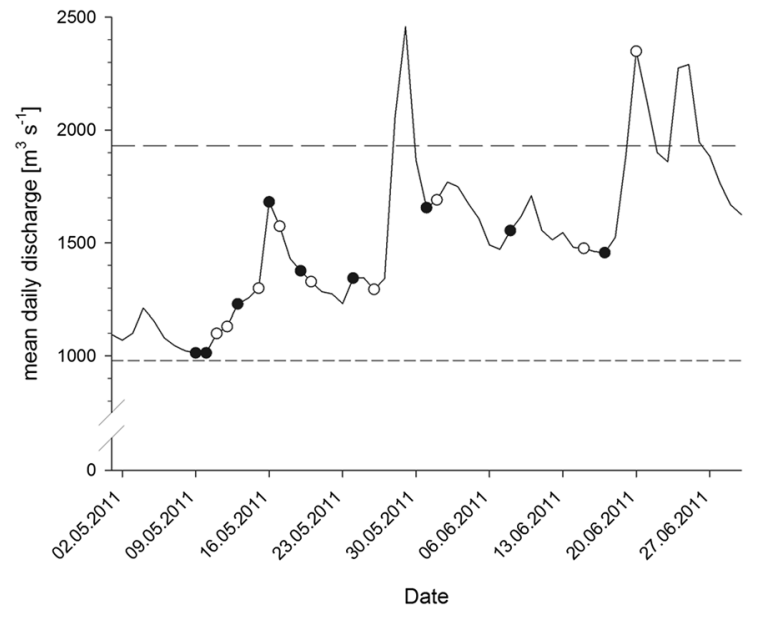

Fig. 3 Mean daily discharge of the Danube (hydrological station at Wildungsmauer) during the sampling period. Sampling dates are indicated by black dots (near-natural shore) and white circles (stabilized shore). The long-dashed lines indicate the level of discharge at average water level (AWL) and the small-dashed lines the discharge at low navigation and regulation level (LNRL) as specified in via donau (2012)

by performing linear regression analyses for each genus, with date as the predictor variable and size as the dependent variable.

The discriminant analysis and ANOVA bootstrap calculations were performed by the program routine 'MUBOQB' (vers. 22 July 2015, implemented on QB64 for linux, (C H.L. Nemeschkal). The $G$-test was implemented as a Libreoffice-Calc-macro (vers. 4.1.6.2-40, openSUSE-13.1, (C) H.L. Nemeschkal). Diagrams were generated, and linear regressions fitted, using SigmaPlot 12.0 (Systat Software, San Jose, USA).

\section{Results}

General

Discharge ranged from 1,013 to $2,458 \mathrm{~m}^{3} \mathrm{~s}^{-1}$ during the sampling months May and June, with a mean daily discharge of $1,529 \mathrm{~m}^{3} \mathrm{~s}^{-1}$ (Fig. 3). The mean daily discharge was below the discharge of average water level which is set to $1,930 \mathrm{~m}^{3} \mathrm{~s}^{-1}$ in this section of the Danube (via donau, 2012). The highest discharge was clearly below the threshold of the discharge at the highest navigable water level of $5,130 \mathrm{~m}^{3} \mathrm{~s}^{-1}$ (via donau, 2012), indicating that no larger flood events have occurred during the investigation period.
A total of 984 drift samples (i.e. nets) were examined, containing 29,163 individual fishes from five families (Table 3). Cyprinidae $(n=21,037$, $72.1 \%$ of total catch) accounted for the highest abundances, followed by Gobiidae $(n=6,346$, $21.8 \%)$ and Percidae $(n=1,754,6.0 \%)$. The families Cottidae and Gasterosteidae were represented by 21 and 5 individuals, respectively. More individuals drifted along the near-natural shore than the stabilized shore. The focus of this paper is on percids and gobiids, and so further analyses will be limited to these two families.

\section{Temporal distribution}

In both gobiids and percids, sampling date and sampling hour had a significant effect on the DD (all $P<0.001$; Table 4). The seasonal pattern of drift was specific for each genus and was characterized by differences in mean DD, as well as different timing and number of peaks (Fig. 4; a detailed list of the DD of all genera is provided in Online Resource 1).

Gobiids started to drift in the second week of May and showed constantly high DD throughout the remaining sampling period, with several peaks. Significant differences between the shores were found for Neogobius $(P<0.001, G=1,022.24)$.

Percid genera were present in the samples from the first sampling day. The $G$-test revealed significant differences between the seasonal patterns along the near-natural and stabilized shore in Sander $(P=0.002$, $G=23.98)$ and Zingel $(P<0.001, G=162.89)$.

The timing of sunset varied from $20: 17$ to $20: 56$ (summer time, CEST) during the sampling period. Gobiids were almost absent in the drift before dusk. Percids were already drifting before sunset (Fig. 5). DD remained comparably low until 20:00 (Sander, Zingel) or 21:00 (Perca, Gymnocephalus), respectively, followed by a strong increase. In both families, the DD continuously increased along the near-natural shore after sunset. On the stabilized shore, however, DD dropped after 22:00 in most genera (Proterorhinus, Neogobius, Perca, Sander). We found significant differences of the diel drift patterns between the shores in Neogobius $(P<0.001, G=152.18), \quad$ Sander $(P<0.001, G=26.70)$, and Zingel $(P=0.002$, $G=17.38$ ). In Proterorhinus, Perca, and Gymnocephalus, the null hypotheses (i.e. no differences in drift patterns between the shores) persist. 
Table 1 Sampling dates, temperature, and mean daily discharge along the sampled near-natural gravel bar and stabilized rip-rap shore

\begin{tabular}{|c|c|c|c|c|c|c|c|c|c|}
\hline \multirow[t]{2}{*}{ Shores } & \multirow[t]{2}{*}{ Dates } & \multirow[t]{2}{*}{ Temperature $\left({ }^{\circ} \mathrm{C}\right)$} & \multirow[t]{2}{*}{ Discharge $\left(\mathrm{m}^{3} \mathrm{~s}^{-1}\right)$} & \multicolumn{3}{|l|}{ Time } & \multicolumn{3}{|c|}{ Number of nets } \\
\hline & & & & Start & End & Sunset & Day & Night & Total \\
\hline \multirow[t]{10}{*}{ Near-natural } & 9 May 2011 & 15.5 & $1,013.4$ & $20: 30$ & $22: 30$ & $20: 17$ & 0 & 36 & 36 \\
\hline & 10 May 2011 & 17.5 & $1,013.0$ & $19: 00$ & 23:00 & 20:19 & 24 & 36 & 60 \\
\hline & 13 May 2011 & 17.5 & $1,228.7$ & $19: 00$ & 23:00 & $20: 23$ & 24 & 36 & 60 \\
\hline & 16 May 2011 & 16.2 & $1,681.0$ & $19: 00$ & 23:00 & $20: 27$ & 24 & 36 & 60 \\
\hline & 19 May 2011 & 17.9 & $1,375.3$ & $19: 30$ & $23: 30$ & $20: 30$ & 24 & 36 & 60 \\
\hline & 24 May 2011 & 19.4 & $1,343.1$ & $19: 30$ & $23: 30$ & $20: 36$ & 24 & 36 & 60 \\
\hline & 31 May 2011 & 17.9 & $1,655.4$ & 20:00 & 0:00 & $20: 44$ & 12 & 36 & 48 \\
\hline & 8 June 2011 & 19.2 & $1,554.3$ & $20: 30$ & $23: 30$ & $20: 50$ & 12 & 36 & 48 \\
\hline & 17 June 2011 & 19.3 & $1,456.2$ & $20: 30$ & $23: 30$ & $20: 55$ & 12 & 36 & 48 \\
\hline & & & & & & $\Sigma$ & 156 & 324 & 480 \\
\hline \multirow[t]{11}{*}{ Stabilized } & 11 May 2011 & 16.4 & $1,099.3$ & $19: 30$ & $23: 30$ & $20: 20$ & 12 & 48 & 60 \\
\hline & 12 May 2011 & 17.1 & $1,130.0$ & 19:00 & 23:00 & $20: 21$ & 24 & 36 & 60 \\
\hline & 15 May 2011 & 15.9 & $1,298.2$ & $19: 00$ & 23:00 & $20: 25$ & 24 & 36 & 60 \\
\hline & 17 May 2011 & 16.0 & $1,573.5$ & 19:00 & 23:00 & $20: 28$ & 24 & 36 & 60 \\
\hline & 20 May 2011 & 18.3 & $1,327.0$ & $19: 30$ & $23: 30$ & $20: 32$ & 24 & 36 & 60 \\
\hline & 26 May 2011 & 19.5 & $1,292.8$ & $19: 30$ & $23: 30$ & $20: 38$ & 24 & 36 & 60 \\
\hline & 1 June 2011 & 18.4 & $1,690.0$ & $20: 30$ & $23: 30$ & $20: 45$ & 12 & 36 & 48 \\
\hline & 15 June 2011 & 20.1 & $1,475.7$ & $20: 30$ & $23: 30$ & $20: 54$ & 12 & 36 & 48 \\
\hline & 20 June 2011 & 18.0 & $2,349.1$ & $20: 30$ & $23: 30$ & $20: 56$ & 12 & 36 & 48 \\
\hline & & & & & & $\Sigma$ & 168 & 336 & 504 \\
\hline & & & & & & Total $\Sigma$ & 324 & 660 & 984 \\
\hline
\end{tabular}

Additionally, start and end time of sampling (hourly intervals), timing of sunset, and number of samples (nets) taken before (day) and after sunset (night) are shown

Size

The size distributions of the early life stages of the percid genera in the drift were different from the gobiids (Table 5). No, or only a marginal, increase in mean size was found for the gobiids (Fig. 6a, b; Table 6), with more than $95 \%$ of all captured gobies drifting at sizes smaller than $10 \mathrm{~mm}$ TL. This indicates multiple spawning events, as well as a size- and stagespecific drift in these genera.

Mean and minimum size substantially increased in percid genera throughout the sampling period (all $P<0.001$, all $R^{2}>0.5$; Fig. 6c-f; Table 6). For instance, more than $50 \%$ of all individuals of Sander drifted at sizes larger than $20 \mathrm{~mm}$ TL. Sander also showed the greatest maximum lengths. The smallest mean and maximum length was found in Gymnocephalus (Table 5).

\section{Spatial distribution}

Significant differences in DDs were found between the stabilized and the near-natural shore for both gobiids and percids (all $P<0.001$ ). The mean DD of gobiids was four times higher along the stabilized shore than along the near-natural shore, whereas the mean DD of percids was twice as high along the near-natural shore as along the stabilized bank. The DD of gobiids was almost 10 times higher than that of percids on the stabilized shore, whereas this ratio was only 1:1.2 at the near-natural shore (Table 3).

Sampling locations had statistically significant effects on DD in gobiids ( $P$-values ranging from 0.083 to smaller than 0.001 ). No significant effect of sampling location on DD was found in percids (all $P>0.05)$. In both gobiids and percids, no statistical 
Table 2 Scientific and common names of gobiids and percids in the Austrian Danube

\begin{tabular}{llllll}
\hline Species & Authors & Common names & Status & Ecological guild & Spawning guild \\
\hline Gobiidae & & & & & \\
Neogobius gymnotrachelus & $($ Kessler, 1857) & Racer goby & Invasive & Eurytopic & Euryopar \\
N. kessleri & (Günther, 1861) & Bighead goby & Invasive & Eurytopic & Euryopar \\
N. melanostomus & (Pallas, 1814) & Round goby & Invasive & Eurytopic & Euryopar \\
Proterorhinus semilunaris & $($ Heckel, 1837) & Western tubenose goby & EN & Eurytopic & Euryopar \\
Percidae & & & & & Rheophilic \\
Gymnocephalus baloni & Holcik \& Hensel, 1974 & Danube ruffe & VU & Limnopar \\
G. cernua & (L., 1758) & Ruffe & LC & Eurytopic & Euryopar \\
G. schraetser & (L., 1758) & Schraetzer & VU & Rheophilic & Rheopar \\
Perca fluviatilis & L., 1758 & Perch & Eurytopic & Euryopar \\
Sander lucioperca & (L., 1758) & Pikeperch & NT & Eurytopic & Euryopar \\
S. volgensis & (Gmelin, 1789) & Volga pikeperch & EN & Limnophilic & Euryopar \\
Zingel streber & (Siebold, 1863) & Streber & EN & Rheophilic & Rheopar \\
Z. zingel & (L., 1758) & Zingel & VU & Rheophilic & Rheopar \\
\hline
\end{tabular}

In addition, threat status, habitat, and spawning requirements (ecological and spawning guilds) are provided. The affiliation to guilds follows Schiemer \& Waidbacher (1992) and Zauner \& Eberstaller (1999). The classification under a category of threat or as invasive is based on Wolfram \& Mikschi (2007) and Wiesner et al. (2010)

$E N$ endangered, $L C$ least concern, $N T$ near threatened, $V U$ vulnerable

${ }^{\text {a }}$ Only the populations east from Vienna are considered as native and endangered, elsewhere in Austria this species too is regarded as invasive

Table 3 Number of individuals ( $n$ ), percentage of total catch, mean drift density (DD), and standard deviation (SD) for all families which were caught in the drift

\begin{tabular}{|c|c|c|c|c|c|c|c|c|c|c|}
\hline \multirow[t]{2}{*}{ Taxon } & \multicolumn{5}{|c|}{ Near-natural shore } & \multicolumn{5}{|c|}{ Stabilized shore } \\
\hline & $n$ & Percentage & & Mean DD & SD & $n$ & Percentage & & Mean DD & SD \\
\hline Gobiidae & 1,832 & 11.3 & & 2.95 & 5.18 & 4,514 & 34.9 & & 12.15 & 25.00 \\
\hline Proterorhinus & 44 & 0.3 & 2.4 & 0.07 & 0.25 & 22 & 0.2 & 0.5 & 0.08 & 0.45 \\
\hline Neogobius & 1,788 & 11.0 & 97.6 & 2.87 & 5.13 & 4,492 & 34.8 & 99.5 & 12.02 & 24.96 \\
\hline Percidae & 1,309 & 8.1 & & 2.44 & 3.71 & 445 & 3.4 & & 1.16 & 1.79 \\
\hline Perca & 69 & 0.4 & 5.3 & 0.12 & 0.40 & 22 & 0.2 & 4.9 & 0.04 & 0.22 \\
\hline Sander & 618 & 3.8 & 47.2 & 1.06 & 2.00 & 155 & 1.2 & 34.8 & 0.38 & 0.88 \\
\hline Gymnocephalus & 48 & 0.3 & 3.7 & 0.09 & 0.36 & 69 & 0.5 & 15.5 & 0.21 & 0.95 \\
\hline Zingel & 574 & 3.5 & 43.9 & 1.16 & 2.67 & 199 & 1.5 & 44.7 & 0.52 & 1.18 \\
\hline Cyprinidae & 13,095 & 80.6 & & 30.65 & 59.94 & 7,942 & 61.5 & & 28.55 & 95.18 \\
\hline Cottidae & 3 & $<0.1$ & & $<0.10$ & 0.05 & 18 & 0.1 & & 0.04 & 0.25 \\
\hline Gasterosteidae & 3 & $<0.1$ & & 0.01 & 0.07 & 2 & $<0.1$ & & 0.01 & 0.13 \\
\hline$\Sigma$ & 16,242 & $(55.7 \%)$ & & & & 12,921 & $(44.3 \%)$ & & & \\
\hline Total $\Sigma$ & 29,163 & $(100 \%)$ & & & & & & & & \\
\hline
\end{tabular}

The genera of the Gobiidae and Percidae are additionally listed. For the genera, the left column of the percentage gives the share of the total catch, while the right column gives the share within the respective family 
Table 4 Results of the ANOVA via GLM for gobiids (upper rows) and percids (lower rows), using the drift density (DD) as criterion, sampling station $\left(b_{1}-b_{3}\right)$ and distance from shore $\left(b_{4}-b_{5}\right)$ as factors, and sampling day $\left(b_{6}\right)$ and hour $\left(b_{7}\right)$ as co-variates
$b_{O}$ constant, $S E$ standard

error

Asterisks indicate level of significance (Sign.):

** $P<0.01$,

*** $P<0.001$, n.s. not

significant

\begin{tabular}{lclll}
\hline Regression coefficients & Parameter values & SE & $P$ value & Sign. \\
\hline Gobiidae & & & & \\
$b_{0}$ & -110.066 & 9.502 & $<0.001$ & $* * *$ \\
$b_{1}$ & 1.930 & 1.163 & 0.083 & n.s. \\
$b_{2}$ & 3.654 & 1.393 & 0.005 & $* *$ \\
$b_{3}$ & 5.571 & 1.593 & $<0.001$ & $* * *$ \\
$b_{4}$ & -0.333 & 1.410 & 0.806 & n.s. \\
$b_{5}$ & -0.291 & 1.334 & 0.815 & n.s. \\
$b_{6}$ & 0.230 & 0.039 & $<0.001$ & $* * *$ \\
$b_{7}$ & 3.877 & 0.356 & $<0.001$ & $* * *$
\end{tabular}

Coefficient of determination 0.1313

Percidae

$b_{0}$

$b_{1}$

$b_{2}$

$b_{3}$

$b_{4}$

$b_{5}$

$b_{6}$

$b_{7}$

$\begin{array}{lll}1.294 & <0.001 & * * * \\ 0.256 & 0.079 & \text { n.s. } \\ 0.280 & 0.607 & \text { n.s. } \\ 0.282 & 0.818 & \text { n.s. } \\ 0.210 & 0.086 & \text { n.s. } \\ 0.221 & 0.089 & \text { n.s. } \\ 0.006 & <0.001 & * * * \\ 0.075 & <0.001 & * * *\end{array}$

Coefficient of determination 0.1489 differences were found regarding distance from the shore (Table 4).

Of the gobiids, the genus Neogobius, which represents three invasive species, was overwhelmingly dominant (Table 3). Proterorhinus accounted for only $1 \%$ of all gobiids in the catch. The proportion of Proterorhinus, among the total catch of gobiids, was higher on the near-natural shore than on the stabilized bank. There was a significantly higher DD of early stages of Neogobius along the stabilized shore than on the near-natural shore $(P<0.001)$.

Most percids collected in drift nets belonged to the genus Zingel, followed by Sander, whereas Gymnocephalus and Perca were found at relatively low DD (Table 3). More individuals from Perca were drifting along the near-natural shore, whereas the DD of Gymnocephalus was higher on the stabilized shore, mainly due to a single peak on May 17. Sander and Zingel exhibited significantly greater DD along the near-natural shoreline than along the stabilized shoreline (all $P<0.001$ ).

\section{Discussion}

General

Although consisting of fewer species, the gobiids drifted in significantly higher densities than the percids. In this study, the three Neogobius species alone were responsible that the Gobiidae were the second most abundant family in the drift. Moreover, gobiids are also known as the dominant family in other drift studies (Zitek et al., 2004b; Lechner et al., 2010). The general dominance of the Neogobius species over the genus Proterorhinus is likely a result of their high invasive potential and possibly reflects the effects of direct competition (Wolfram \& Mikschi, 2007; Wiesner et al., 2010).

The genera Zingel and Sander showed the highest DD among the Percidae but are generally only rarely caught as adults (Schabuss \& Reckendorfer, 2002; Erős et al., 2008; Keckeis, 2013; Loisl et al., 2013). Their high abundances as early life stages, but low 
Proterorhinus

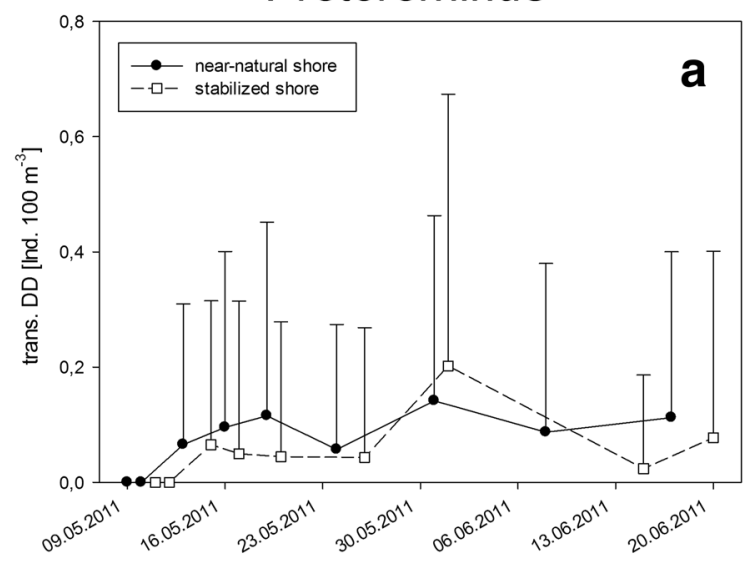

Perca

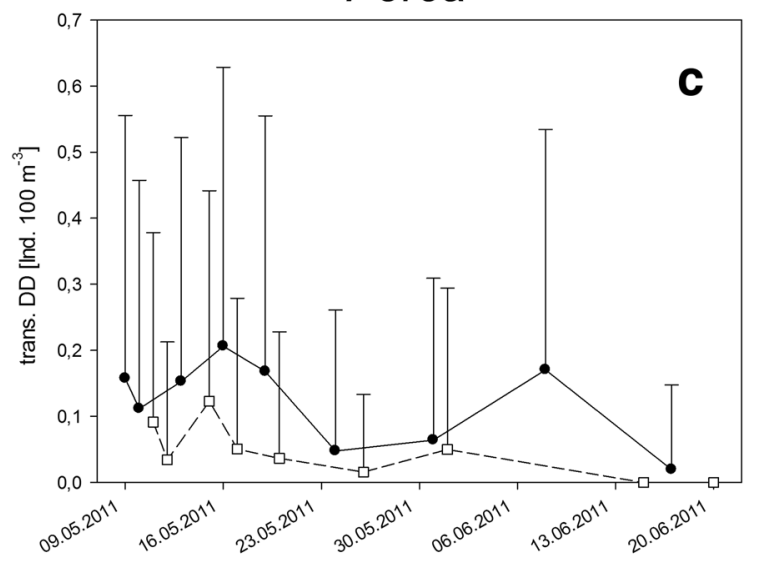

Gymnocephalus

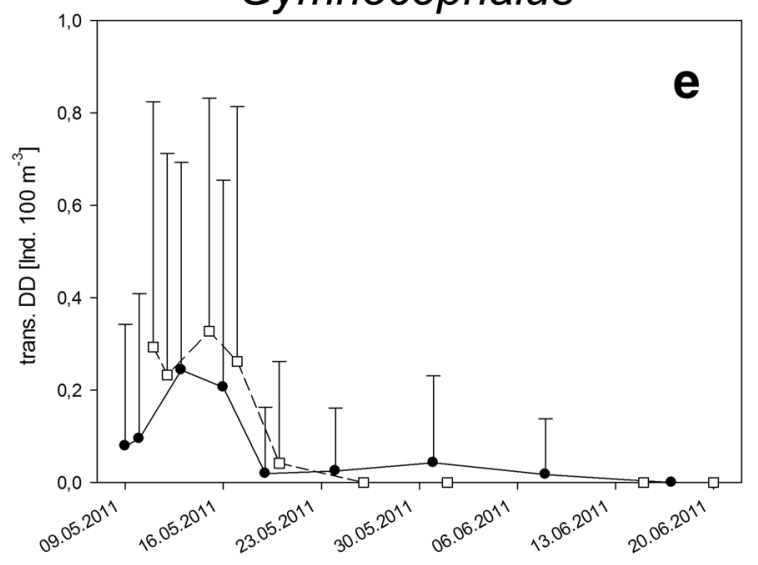

Date

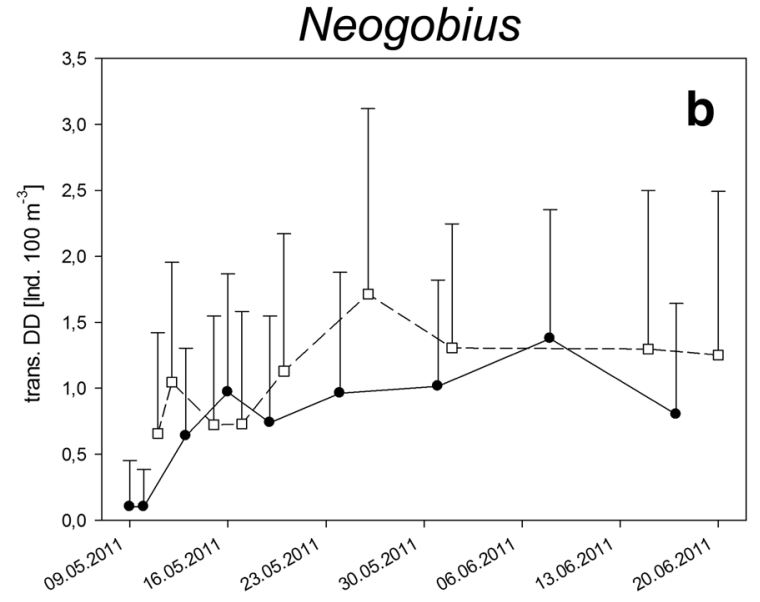

Sander

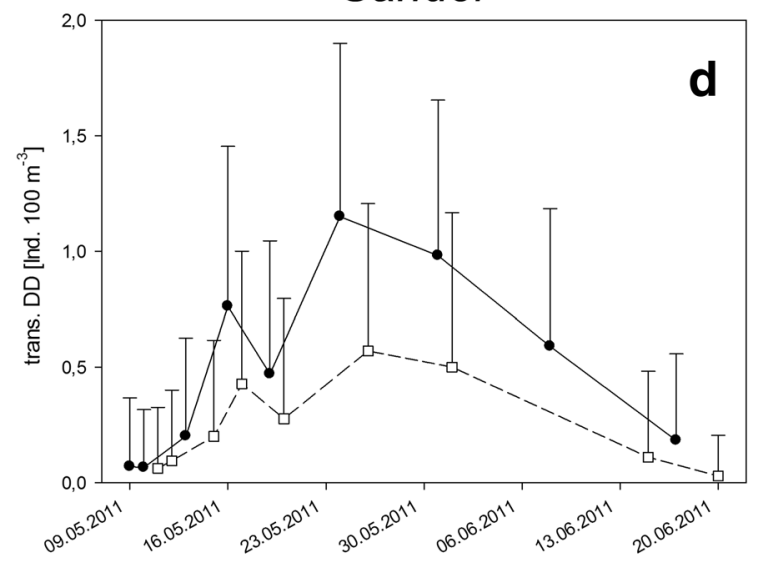

Zingel

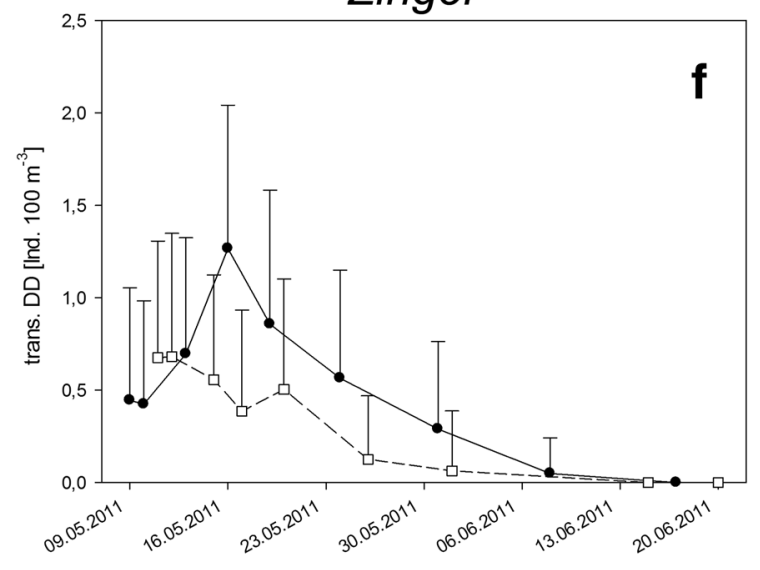

Date

Fig. 4 Seasonal patterns of mean drift densities of gobiid $(\mathbf{a}, \mathbf{b})$ and percid $(\mathbf{c}-\mathbf{f})$ genera. Transformed data (see text for further information). Note that the $y$-axes are differently scaled 

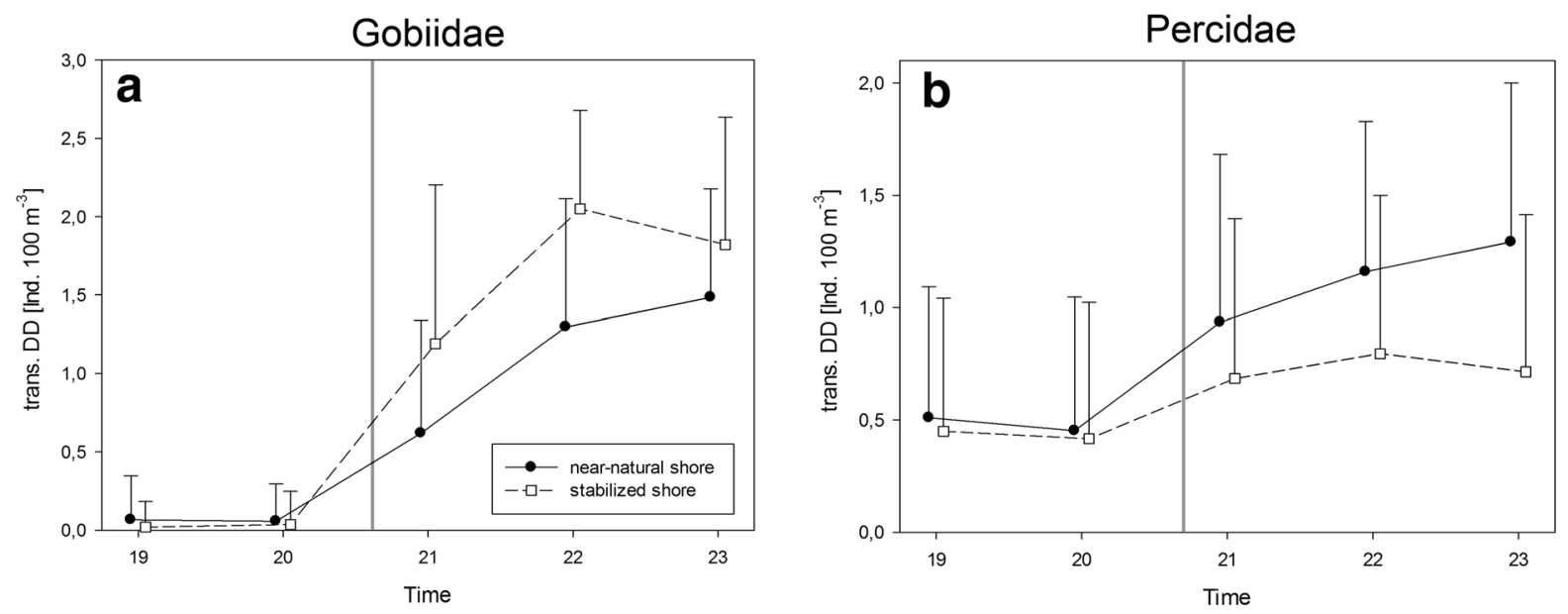

Fig. 5 Diel patterns of mean drift densities (DDs) of Gobiidae (a) and Percidae (b). Transformed data (see text for further information). The vertical lines indicate the average timing of sunset during the sampling period

Table 5 Number of measured individuals, mean size, standard deviation (SD), minimum and maximum sizes (total length in $\mathrm{mm}$ ) in drifting gobiids (upper rows) and percids (lower rows)

\begin{tabular}{lrrlll}
\hline Genus & $n$ & Mean & SD & Min & Max \\
\hline Proterorhinus & 67 & 6.6 & 1.0 & 5 & 12 \\
Neogobius & 6,255 & 8.6 & 1.2 & 6 & 22 \\
Perca & 91 & 14.8 & 7.6 & 6.5 & 37 \\
Sander & 773 & 22.2 & 6.7 & 8 & 57 \\
Gymnocephalus & 116 & 7.0 & 2.8 & 4 & 20 \\
Zingel & 768 & 10.4 & 3.6 & 6 & 35 \\
Total $\Sigma$ & 8,070 & & & & \\
\hline
\end{tabular}

Note that the total number of individuals is lower than in Table 3, because size measurement was not possible for all specimens

adult abundances, point to either high mortality rates of young fish, or a lack of efficient sampling methods for adult stages of these genera. In contrast, the monotypic genus Perca showed comparably low drifting densities, but the perch ( $P$. fluviatilis) is often the most abundant adult percid in the Danube and its backwaters (Schabuss \& Reckendorfer, 2002; Loisl et al., 2013). This supports the suggestion of some authors that this species avoids drifting (Reichard et al., 2002b; Zitek et al., 2004b) but may likewise be because of a preference for backwaters, also for reproduction (Schabuss \& Reckendorfer, 2002; Hohausova \& Jurajda, 2005).

At any rate, our results not only show that all percid genera are able to reproduce in the Danube but also illustrate the importance of near-natural shores for spawning and development. Furthermore, we were able to identify some of the late larvae and juveniles to species level and can confirm a successful natural reproduction of almost all percid species, including the endangered streber (Z. streber) and Volga pikeperch (S. volgensis). Only the Danube ruffe (G. baloni) were not able to be unambiguously identified.

Temporal distribution and size

Substantial differences of drift patterns between, as well as within, percid and gobiid genera were found, including DDs, seasonal and diel patterns, and size structure.

Seasonality was generally highly specific for each genus. The gobiid drift was characterized by several peak abundances, without any recognizable (e.g. uni-, bimodal) pattern (Fig. 4a, b). The first peak in DD in Proterorhinus may be attributable to the increase in discharge. However, there is no corresponding peak in Neogobius. Gobiids showed constantly moderate to high DDs and were still drifting in late June. It is likely that the gobiids were spawning continuously throughout the sampling period, because both mean and minimum sizes of Proterorhinus and Neogobius remained constant throughout May and June and recently hatched individuals were found even at the last sampling days. A prolonged spawning period from approximately April to September is thought to occur for these species (Miller, 2004; Janáč et al., 2013). 

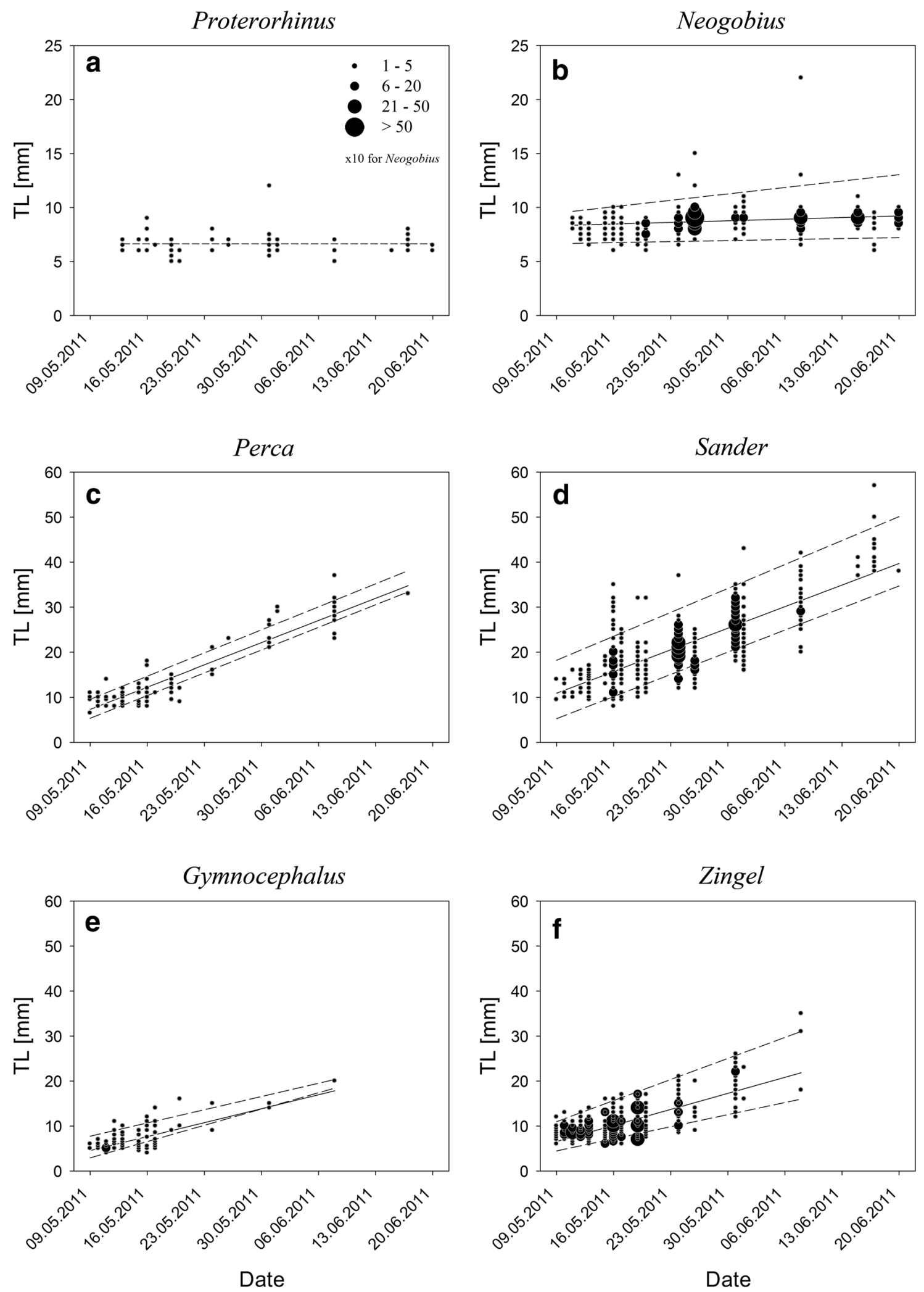
4Fig. 6 Size changes throughout sampling period in gobiids (a, b) and percids (c-f). Both shores are grouped together. Black line linear regression of mean sizes per day, medium dashed lines linear regression of the minimum and maximum sizes of each day. The short dashed line in Proterorhinus indicates the mean size, as the slope of the regression line was not significantly different from zero (see also Table 6). Bubble size indicates the number of caught individuals of a given size per day; an explanatory legend is given in a. Note that the $y$-axes are differently scaled for gobiids and percids

This may lead to an advantage of gobiids over most native fishes which inhabit similar habitats and could be one explanation for their high invasive success. Janáč et al. (2013) found a similar multimodal and prolonged seasonal pattern of Neogobius in the River Dyje (Czech Republic, Danube Basin), although with a later onset of drift activity. The seasonality of drift intensity found in Proterorhinus matches only partially with other studies. In a study in an artificial sidearm of the Austrian Danube, Proterorhinus was the dominant genus and exhibited a slightly bimodal seasonal pattern, with high DD throughout June and very low values in late May and early August (Zitek et al., 2004a). In contrast, Janáč et al. (2013) found maximum DD in May and almost no specimens of Proterorhinus after mid-June in the Dyje. Drifting in Proterorhinus seems therefore variable, and continuous spawning may not always occur.

In our study, the Neogobius species had larger mean (and also minimum and maximum) body sizes than Proterorhinus (Table 5). This could lead to competitive advantages, which may contributes to the decline of P. semilunaris in the Danube (Mikschi et al., 1996; Wolfram \& Mikschi, 2007) and the resulting low abundances in the drift. More than $95 \%$ of all caught gobies drifted at sizes smaller than $10 \mathrm{~mm}$ TL. This reflects an early and rapid shift to a benthic lifestyle, along with a corresponding drift avoidance. Proterorhinus and Neogobius hatch at a late stage of larval development (Moskal'kova, 1996), and it appears that dispersal is restricted to these late early life stages. Subsequently, dispersal is followed by settlement in, and exploitation of, benthic habitats. Information on the settlement of early life stages of gobiids is very limited. They usually hide between stones and rocks, which makes them hard to catch with dip nets, and their lack of a swim bladder complicates the use of electrical fishing gear, as they would sink rather than float after electro-immobilization. As the abundance of early stages of gobiids may often be underestimated, drift analyses can help in establishing more accurate relative abundances.

The seasonal drift patterns in the percid genera shows generally one or two peak abundances (Fig. 4cf). Only Perca exhibited more than two maxima of drift activity (Fig. 4c). However, as the percids were already drifting in substantial numbers at the first sampling date, we may have not covered the whole drifting season, and it is therefore possible that we have missed earlier peaks. Nevertheless, the main drift activity in percids appears to take place in May. Bi- or multimodal patterns could reflect repeated spawning events; however, minimum sizes in all percid genera increased during the sampling period. Therefore, no newly hatched larvae emerged in the drift beyond a certain time, indicating a rather short spawning season for all percids. The peaks in the DD have thus to be linked to other factors than spawning behaviour. Analogous to gobiids, it appears that (only) the first peak in drift occurrence of most genera was influenced

Table 6 Regression coefficients and statistical significance of the linear regression on size and date, as well as coefficient of determination $\left(R^{2}\right)$ of gobiid (upper rows) and percid (lower rows) genera in the drift

\begin{tabular}{|c|c|c|c|c|c|}
\hline \multirow[t]{2}{*}{ Genus } & \multicolumn{4}{|c|}{ Regression coefficients } & \multirow[t]{2}{*}{$R^{2}$} \\
\hline & Constant & Sign. & Slope & Sign. & \\
\hline Proterorhinus & 6.65 & $P<0.001$ & -0.001 & $P=0.944$ & $<0.001$ \\
\hline Neogobius & 8.30 & $P<0.001$ & 0.022 & $P<0.001$ & 0.053 \\
\hline Perca & 6.63 & $P<0.001$ & 0.704 & $P<0.001$ & 0.860 \\
\hline Sander & 10.22 & $P<0.001$ & 0.685 & $P<0.001$ & 0.584 \\
\hline Gymnocephalus & 4.10 & $P<0.001$ & 0.443 & $P<0.001$ & 0.519 \\
\hline Zingel & 6.05 & $P<0.001$ & 0.509 & $P<0.001$ & 0.526 \\
\hline
\end{tabular}


by discharge (Fig. 3), probably as a function of the location of spawning habitat. To our knowledge, our study is the first to produce drift patterns for all percid genera in the Danube. Oesmann (2003) has sampled the River Elbe (Germany) for drifting fish larvae, though only throughout May. The abundance values from his data suggest a very similar seasonal pattern in Gymnocephalus, and Perca. Regarding Sander, drifting seems to start and end earlier in the Elbe. Another similarity to our data was that Sander was the most abundant genus, followed by much lower values for Perca and Gymnocephalus (the genus Zingel is absent in the Elbe).

In percids, ontogenetic switches (from pelagic to benthic) may be accompanied by a migration to, and settlement in, near-shore habitats. Once the young fish are settled, drifting and thus their first long-range dispersal are probably complete (Coles, 1981; Miehls \& Dettmers, 2011). Nevertheless, a habitat switch to benthic near-shore areas seems to coincide with the end of the drifting phase. Gymnocephalus and Zingel show a rather brief pelagic phase, because the majority of early life stages drift at sizes $<15 \mathrm{~mm}$ TL (Fig. 6). Broader time ranges were exhibited by Perca and Sander, with larger proportions of drifting late larvae and juveniles compared to the other two percid genera. This is in concordance with other studies, which report a relatively long pelagic phase, followed by a switch to benthic habitats between 20 and $30 \mathrm{~mm}$ TL for Perca (Spanovskaya \& Grygorash, 1977; Coles, 1981; Miehls $\&$ Dettmers, 2011) and Sander (Specziár, 2005). Similar data for Gymnocephalus and Zingel are lacking.

Differences were also found for the diel drift patterns between gobiids and percids (Fig. 5). During the day, the former were virtually absent in the drift, while the latter were already drifting at the beginning of sampling. Illumination level is a key factor in fish larvae drift and usually negatively correlated with DD (Reichard et al., 2002a), resulting in the highest DD between dusk and dawn (Pavlov, 1994; Reichard et al., 2002a; Zitek et al., 2004a). The ultimate reason behind this fact, however, is still not clear. Proposed explanations include not only active following of prey (Armstrong \& Brown, 1983), or inversely predator avoidance (Corbett \& Powles, 1986; Harvey, 1991), but also passive displacement due to loss of visual orientation (Pavlov et al., 1978; Pavlov, 1994). According to the results of the present study, percids seem to be less influenced by such factors.
The reason why DD drops after 22:00 along the stabilized bank in four of the six genera remains unclear. A similar pattern of nocturnal drift of gobiids, with a peak at approximately 22:00, followed by a decrease (although a rather sharp one) was described for Russian waters (Pavlov et al., 1978). In a study in which $24 \mathrm{~h}$ samples were taken in the Danube (Keckeis, unpublished data), the diel changes in drift intensity were very similar to our data for both gobiids and percids. However, DD varied during the day and maximum values were found at (gobiids), or shortly after (percids), midnight. Janáč et al. (2013), who have monitored drift patterns in the River Dyje from sunset to sunrise, found differences in the nocturnal drift patterns between $N$. melanostomus and P. semilunaris. While the abundance of the former rapidly decreased after a peak $2.5 \mathrm{~h}$ after dusk, numbers of the latter varied until dawn. Other studies in turn suggested that the loss of information is acceptable if only the first few hours of darkness are sampled (Persat \& Olivier, 1995; Zitek et al., 2004a). This assumption, however, may be too simplified. The increase in DD after dusk is well supported from previous studies (Pavlov et al., 1978; Brown \& Armstrong, 1985; Zitek et al., 2004a; Janáč et al., 2013). It appears though that the onset und duration of drift activities during the night is variable and is likely dependent on local factors such as turbidity and others (Pavlov, 1994).

\section{Spatial distribution}

Clear differences in DD exist between the two shores, which may be caused by abiotic (e.g. river hydraulics, shore morphology, etc.) or biotic (e.g. behaviour, foraging, predation, etc.) factors. It is therefore of high importance to differentiate between shore types, even within the same river section.

Gobiids drifted at higher densities on both shores compared to percids. However, the different ratios of gobiids-percids indicate different shore specific qualities for the families. The gobies occurring in Austria can be classified as eurytopic (Schiemer \& Waidbacher, 1992; Ahnelt et al., 1998) and can thrive on many substrates (Kottelat \& Freyhof, 2007; Wiesner et al., 2010; Kornis et al., 2012). In contrast, Percidae comprise several habitat specialists (Schiemer \& Waidbacher, 1992; Spindler, 1997; Kottelat \& Freyhof, 2007). The higher proportion of percids along the near-natural shore may therefore reflect a higher 
suitability as a spawning ground for adults and a higher retention capacity and habitat suitability for the early life stages. The view of more natural shores being more suitable for native species is further corroborated by the higher abundance of cyprinids on this shore (Table 3). It should be noted though that we do not know which genera are among the caught cyprinid specimens. The cyprinids of Austria consist of more than 30 native (Wolfram \& Mikschi, 2007) and 6 exotic species (Wiesner et al., 2010). However, only two exotic species $(<6 \%)$, the goldfish Carassius auratus (Linnaeus 1758) and the stone moroko Pseudorasbora parva (Temminck \& Schlegel 1846), are considered established (Wiesner et al., 2010). It is therefore implausible that invasive cyprinids are the cause for the differences in DD between the shores. Gravel bars are generally considered as most suitable for the early life stages of most riverine (rheophilic) species (Schiemer \& Spindler, 1989; Schiemer et al., 2002). As an example, it was shown for the rheophilic nase carp Chondrostoma nasus, as an indicator species for riverine fishes, that nearnatural shores provide substantially more suitable larval habitats than stabilized shores (Lechner et al., 2013). Based on our results, the same appears to be true for percids.

The results of this study could also be interpreted in the way that a high DD indicates increased dispersal, resulting from an avoidance of suboptimal habitats or density dependent effects. In this scenario, a lower DD along a shore would be due to increased settlement and reflect a higher habitat suitability for early life stages. However, only few studies deal with the settlement of young fish (Schludermann et al., 2012; Keckeis, 2013; Lechner et al., 2013). In addition, members of the Percidae and Gobiidae are rarely observed or completely absent in PAS catches (Persat \& Copp, 1990) in nursery habitats at inshore areas (Copp \& Peňáz, 1988; Keckeis, 2013). The analysis of drift samples is thus the only way to gather useful information on early developmental stages of the examined taxa of this study at all. Although we do not know the exact reasons of drifting (e.g. escapement from unsuitable areas or conditions, shifts between adjacent habitats, or accidental drifting), the occurrence in the samples clearly indicates suitable conditions for spawning, hatching, and also for survival and growth. This holds especially true for the percid genera in the present study. The high number of late larvae and juveniles shows that they were able to survive and go through several developmental stages before they were caught. Early developmental stages are considered as particularly useful as indicators for the ecological integrity of rivers (Schiemer et al., 1991; Schiemer, 2000). As percids and gobiids are both families of high conservational concern, drift studies can serve as a valuable addition to standard methods for the assessment of the status of a river or the effect of restoration measures.

Significant distinctions between the sampling stations were found for the Gobiidae. No such differences were found in percids (Table 4). However, both families show a trend of decreasing DD with distance (Online Resource 2). Lechner et al. (2013), who compared the drift of passive floats and larvae of the nase carp in the same area, showed that the settlement rates of both larvae and floats decreased among adjacent groyne fields, due to hydraulic and hydrological effects. In addition, the groynes along the stabilized shore are long and the groyne heads reach far into the river. Early life stages that re-enter the drift from groyne fields are therefore more likely to get lost in the navigation channel and its very high flow velocities. Settlement in combination with higher losses to the main channel may explain the decrease in percid and gobiid DD along the stabilized shore to some extent. Settlement rates of the rheophilic nase carp were generally low along the stabilized shore (Lechner et al., 2013). This may also be transferable to the percids, given that they also comprise of several rheophilic species. The stronger decrease in DD of gobiids, however, points to high settlement along the groyne fields, which is not unlikely as rocky structures (i.e. rip-rap) are also the preferred habitats of the adults (Charlebois et al., 1997; Kottelat \& Freyhof, 2007).

\section{Conclusion}

The present study identified several differences in drift characteristics for Gobiidae and Percidae along two opposite shores in a free-flowing section of the Austrian Danube. DDs, size of drifting individuals, and seasonal and nocturnal patterns are specific for each family and, for the most part, also genus specific. It is most likely that drift characteristics also differ at species level, which highlights the importance of a differentiation on a low taxonomic 
scale. Even though within the same river section, we found substantial differences in timing and abundance of drifting fishes between the two shores, emphasizing the need to take account of different shore types. Shore-dependent differences of DDs point to an increased suitability of natural shores, with large, shallow areas and concomitant low flow velocity conditions, for percids. The drift along the stabilized shoreline, with a steep shore, covered by large stones, as well as groynes and overall fast flow velocities, was in turn dominated by gobiids, especially by invasive Neogobius species.

Acknowledgments The authors would like to thank A. Lechner, B. Zens, R. Krusch, and F. Lumesberger-Loisl for their help in the field and laboratory. We are grateful to P. Humphries and M. Tritthart for discussion and valuable comments. M. Stachowitsch and P. Humphries improved the English. We also like to extend thanks to R. Fleischhacker for designing the schematic overview (Fig. 2). This study was financed by the Austrian Science Fund (FWF Project MODI P22631-B17 "Modelling dispersal patterns of fish larvae in a large river"). D.R. was supported by a Grant for final theses by the Land Niederösterreich (Lower Austria).

Open Access This article is distributed under the terms of the Creative Commons Attribution 4.0 International License (http:// creativecommons.org/licenses/by/4.0/), which permits unrestricted use, distribution, and reproduction in any medium, provided you give appropriate credit to the original author(s) and the source, provide a link to the Creative Commons license, and indicate if changes were made.

\section{References}

Agresti, A. \& M. Kateri, 2011. Categorical Data Analysis. Springer, Berlin.

Ahnelt, H., 1988. Zum Vorkommen der Marmorierten Grundel (Proterorhinus marmoratus (Pallas), Pisces: Gobiidae) in Österreich. Annalen des Naturhistorischen Museums in Wien 90: 31-42.

Ahnelt, H., P. Banarescu, R. Spolwind, A. Harka \& H. Waidbacher, 1998. Occurrence and distribution of three gobiid species (Pisces, Gobiidae) in the middle and upper Danube region - examples of different dispersal patterns? Biologia 53: 665-678.

Alexander, M., H. Kaiser, O. Weyl \& J. Dick, 2015. Habitat simplification increases the impact of a freshwater invasive fish. Environmental Biology of Fishes 98: 477-486.

Armstrong, M. L. \& A. V. Brown, 1983. Diel drift and feeding of channel catfish alevins in the Illinois River, Arkansas. Transactions of the American Fisheries Society 112: 302-307.
Balon, E. K., 1975. Reproductive guilds of fishes: a proposal and definition. Journal of the Fisheries Board of Canada 32: 821-864.

Balon, E. K., 1990. Epigenesis of an epigeneticist: the development of some alternative concepts on the early ontogeny and evolution of fishes. Guelph Ichthyology Reviews 1: $1-48$.

Baltz, D. M. \& P. B. Moyle, 1993. Invasion resistance to introduced species by a native assemblage of California stream fishes. Ecological Applications 3: 246-255.

Brown, A. V. \& M. L. Armstrong, 1985. Propensity to drift downstream among various species of fish. Journal of Freshwater Ecology 3: 3-17.

Charlebois, P. M., J. E. Marsden, R. G. Goettel, R. K. Wolfe, D. J. Jude \& S. Rudnika, 1997. The round goby, Neogobius melanostomus (Pallas): a review of European and North American literature. Illinois-Indiana Sea Grant Program and the Illinois Natural History Survey Special Publication 20: $1-76$.

Coles, T. F., 1981. The distribution of perch, Perca fluviatilis L. throughout their 1st year of life in Llyn-Tegid, NorthWales. Journal of Fish Biology 18: 15-30.

Copp, G. H., 1997. Microhabitat use of fish larvae and 0+ juveniles in a highly regulated section of the River Great Ouse. Regulated Rivers: Research and Management 13: 267-276.

Copp, G. H. \& M. Peňáz, 1988. Ecology of fish spawning and nursery zones in the flood plain, using a new sampling approach. Hydrobiologia 169: 209-224.

Corbett, B. \& P. Powles, 1986. Spawning and larva drift of sympatric walleyes and white suckers in an Ontario stream. Transactions of the American Fisheries Society 115: 41-46.

de Graaf, G., A. Born, A. Uddin \& S. Huda, 1999. Larval fish movement in the River Lohajang, Tangail, Bangladesh. Fisheries Management and Ecology 6: 109-120.

Erős, T., B. Tóth, A. Sevcsik \& D. Schmera, 2008. Comparison of fish assemblage diversity in natural and artificial rip-rap habitats in the littoral zone of a large river (River Danube, Hungary). International Review of Hydrobiology 93: 88-105.

Fischer, H. B., 1979. Mixing in Inland and Coastal Waters. Academic, New York.

Freeman, M. C., Z. H. Bowen, K. D. Bovee \& E. R. Irwin, 2001. Flow and habitat effects on juvenile fish abundance in natural and altered flow regimes. Ecological Applications 11: 179-190.

Fuiman, L. \& R. Werner (eds), 2002. Fishery Science: The Unique Contributions of Early Life Stages. Blackwell Science, Cornwall.

Grift, R., A. Buijse, W. Van Densen, M. Machiels, J. Kranenbarg, J. Klein Breteler \& J. Backx, 2003. Suitable habitats for 0-group fish in rehabilitated floodplains along the Lower River Rhine. River Research and Applications 19: 353-374.

Harvey, B. C., 1991. Interaction of abiotic and biotic factors influences larval fish survival in an Oklahoma Stream. Canadian Journal of Fisheries and Aquatic Sciences 48: 1476-1480. 
Hohausova, E. \& P. Jurajda, 2005. Restoration of a river backwater and its influence on fish assemblage. Czech Journal of Animal Science 50: 473.

Humphries, P. \& A. King, 2004. Drifting fish larvae in MurrayDarling Basin Rivers: composition, spatial and temporal patterns and distance drifted. In Lintermans, M. \& B. Phillips (eds), Downstream Movement of Fish in the Murray-Darling Basin Statement, Recommendations and Supporting Papers. Murray-Darling Basin Commission, Canberra: 51-58.

Humphries, P. \& P. Lake, 2000. Fish larvae and the management of regulated rivers. Regulated Rivers: Research and Management 16: 421-432.

Humphries, P., L. G. Serafini \& A. J. King, 2002. River regulation and fish larvae: variation through space and time. Freshwater Biology 47: 1307-1331.

Janáč, M. \& P. Jurajda, 2007. A comparison of point abundance and continuous sampling by electrofishing for age- 0 fish in a channelized lowland river. North American Journal of Fisheries Management 27: 1119-1125.

Janáč, M., L. Šlapanský, Z. Valová \& P. Jurajda, 2013. Downstream drift of round goby (Neogobius melanostomus) and tubenose goby (Proterorhinus semilunaris) in their nonnative area. Ecology of Freshwater Fish 22: 430-438.

Keckeis, H., 2013. Short-term effects of inshore restoration measures on early stages, benthic species, and the sublittoral fish assemblage in a large river (Danube, Austria). Hydrobiologia 729: 61-76.

Koblickaya, A., 1981. Identification Keys for Young Freshwater Fishes. Consumer and Food Industry Press, Moscow. (in Russian).

Kornis, M. S., N. Mercado-Silva \& M. J. Vander Zanden, 2012. Twenty years of invasion: a review of round goby Neogobius melanostomus biology, spread and ecological implications. Journal of Fish Biology 80: 235-285.

Kottelat, M. \& J. Freyhof, 2007. Handbook of European Freshwater Fishes. Kottelat, Cornol and Freyhof, Berlin.

Kovac, V., 1994. Early ontogeny of 3 Gymnocephalus species (Pisces, Percidae) - reflections on the evolution of the genus. Environmental Biology of Fishes 40: 241-253.

Kovac, V., 2000. Early development of Zingel streber. Journal of Fish Biology 57: 1381-1403.

Lechner, A., E. Schludermann \& H. Keckeis, 2010. Jungfischdrift in der österreichischen Donau: Taxonomische Zusammensetzung, Entwicklungsstadien und Driftdichte. Österreichs Fischerei 63: 96-100.

Lechner, A., H. Keckeis, E. Schludermann, F. Loisl, P. Humphries, M. Glas, M. Tritthart \& H. Habersack, 2013. Shoreline configurations affect dispersal patterns of fish larvae in a large river. ICES Journal of Marine Science 71: 930-942.

Lechner, A., H. Keckeis, E. Schludermann, P. Humphries, N. McCasker \& M. Tritthart, 2014. Hydraulic forces impact larval fish drift in the free flowing section of a large European river. Ecohydrology 7: 648-658.

Leslie, J. K. \& C. A. Timmins, 2004. Description of age-0 round goby, Neogobius melanostomus Pallas (Gobiidae), and ecotone utilisation in St. Clair Lowland Waters, Ontario. Canadian Field-Naturalist 118: 318-325.

Leslie, J. K., C. A. Timmins \& R. G. Bonnell, 2002. Postembryonic development of the tubenose goby Proterorhinus marmoratus Pallas (Gobiidae) in the St. Clair River/Lake system, Ontario. Archive for Hydrobiology Supplement 154: 341-352.

Loisl, F., G. Singer \& H. Keckeis, 2013. Method-integrated fish assemblage structure at two spatial scales along a freeflowing stretch of the Austrian Danube. Hydrobiologia 729: 77-94.

Mansueti, A. J., 1964. Early development of the Yellow Perch, Perca flavescens. Chesapeake Science 5: 46-66.

McCune, B., J. B. Grace \& D. L. Urban, 2002. Analysis of Ecological Communities, Vol. 28. MjM Software Design, Gleneden Beach.

Miehls, S. M. \& J. M. Dettmers, 2011. Factors influencing habitat shifts of age- 0 yellow perch in southwestern Lake Michigan. Transactions of the American Fisheries Society 140: 1317-1329.

Mikschi, E., G. Wolfram \& A. Wais, 1996. Long-term changes in the fish community of Neusiedler See (Burgenland, Austria). In Kirchhofer, A. \& D. Hefti (eds), Conservation of Endangered Freshwater Fish in Europe. Birkhäuser Verlag, Basel: 111-120.

Miller, P. (ed), 2004. The Freshwater Fishes of Europe. AulaVerlag, Wiebelsheim.

Moskal'kova, K., 1996. Ecological and morphophysiological prerequisites to range extension in the round goby Neogobius melanostomus under conditions of anthropogenic pollution. Journal of Ichthyology 36: 584-590.

Nunn, A. D., G. H. Copp, L. Vilizzi \& M. G. Carter, 2010. Seasonal and diel patterns in the migrations of fishes between a river and a floodplain tributary. Ecology of Freshwater Fish 19: 153-162.

Oesmann, S., 2003. Vertical, lateral and diurnal drift patterns of fish larvae in a large lowland river, the Elbe. Journal of Applied Ichthyology 19: 284-293.

Pavlov, D. S., 1994. The downstream migration of young fishes in rivers - mechanisms and distribution. Folia Zoologica 43: 193-208.

Pavlov, D., A. Pakhorukov, G. Kuragina, V. Nezdoliy, N. Nekrasova, D. Brodskiy \& A. Ersler, 1978. Some features of the downstream migrations of juvenile fish in the Volga and Kuban Rivers. Journal of Ichthyology 19: 363-374.

Pavlov, D., R. Sadkovskii, V. Kostin \& A. Lupandin, 2000. Experimental study of young fish distribution and behaviour under combined influence of baro-, photo- and thermo-gradients. Journal of Fish Biology 57: 69-81.

Pavlov, D. S., V. N. Mikheev, A. I. Lupandin \& M. A. Skorobogatov, 2008. Ecological and behavioural influences on juvenile fish migrations in regulated rivers: a review of experimental and field studies. Hydrobiologia 609: 125-138.

Penaz, M., 2001. A general framework of fish ontogeny: a review of the ongoing debate. Folia Zoologica 50: 241-256.

Persat, H. \& G. Copp, 1990. Electric fishing and point abundance sampling for the ichthyology of large rivers. In Cowx, I.G. (ed), Developments in Electric Fishing. Cambridge University Press, Cambridge: 197-209.

Persat, H. \& J. Olivier, 1995. The first displacements in the early stages of Chondrostoma nasus under experimental conditions. Folia Zoologica 44: 43-50. 
Ramler, D., H. Keckeis \& H. Ahnelt, 2014. Gattungsbestimmung bei Embryonal-, Larval- und Juvenilstadien der Barsche (Percidae) und Meergrundeln (Gobiidae) Österreichs. Österreichs Fischerei 67: 299-307.

Reichard, M. \& P. Jurajda, 2007. Seasonal dynamics and age structure of drifting cyprinid fishes: an interspecific comparison. Ecology of Freshwater Fish 16: 482-492.

Reichard, M., P. Jurajda \& R. Václavík, 2001. Drift of larval and juvenile fishes: a comparison between small and large lowland rivers. Archiv für Hydrobiologie Supplement: Large Rivers 12: 373-389.

Reichard, M., P. Jurajda \& M. Ondračková, 2002a. The effect of light intensity on the drift of young-of-the-year cyprinid fishes. Journal of Fish Biology 61: 1063-1066.

Reichard, M., P. Jurajda \& M. Ondračkovaá, 2002b. Interannual variability in seasonal dynamics and species composition of drifting young-of-the-year fishes in two European lowland rivers. Journal of Fish Biology 60: 87-101.

Reichard, M., P. Jurajda \& C. Smith, 2004. Spatial distribution of drifting cyprinid fishes in a shallow lowland river. Archive for Hydrobiology Supplement 159: 395-407.

Schabuss, M. \& W. Reckendorfer, 2002. Die Hydrologie als Schlüsselparameter für die Verteilung der Adult-und Jungfischfauna im Altarmsystem der Unteren Lobau. Eigenverlag der Universität Wien, Institut für Ökologie und Naturschutz, Vienna.

Scheidegger, K. J. \& M. B. Bain, 1995. Larval fish distribution and microhabitat use in free-flowing and regulated rivers. Copeia 1: 125-135.

Schiemer, F., 2000. Fish as indicators for the assessment of the ecological integrity of large rivers. Hydrobiologia 422/423: 271-278.

Schiemer, F. \& T. Spindler, 1989. Endangered fish species of the Danube River in Austria. Regulated Rivers: Research and Management 4: 397-407.

Schiemer, F. \& H. Waidbacher, 1992. Strategies for conservation of a Danubian fish fauna. River Conservation and Management 26: 363-382.

Schiemer, F., T. Spindler, H. Wintersberger, A. Schneider \& A. Chovanec, 1991. Fish fry associations: important indicators for the ecological status of large rivers. Verhandlungen der Internationalen Vereinigung für Theoretische und Angewandte Limnologie 24: 2497-2500.

Schiemer, F., H. Keckeis \& E. Kamler, 2002. The early life history stages of riverine fish: ecophysiological and environmental bottlenecks. Comparative Biochemistry and Physiology, Part A: Molecular and Integrative Physiology 133: 439-449.

Schludermann, E., M. Tritthart, P. Humphries, H. Keckeis \& M. J. Bradford, 2012. Dispersal and retention of larval fish in a potential nursery habitat of a large temperate river: an experimental study. Canadian Journal of Fisheries and Aquatic Sciences 69: 1302-1315.

Sokal, R. \& F. Rohlf, 1995. Biometry, 3rd ed. WH Freeman and Company, New York.
Sonny, D., S. Jorry, X. Wattiez \& J. Philippart, 2006. Interannual and diel patterns of the drift of cyprinid fishes in a small tributary of the Meuse River, Belgium. Folia Zoologica 55: 75.

Spanovskaya, V. D. \& V. A. Grygorash, 1977. Development and food of age-0 Eurasian perch (Perca fluviatilis) in reservoirs near Moscow, USSR. Journal of the Fisheries Research Board of Canada 34: 1551-1558.

Specziár, A., 2005. First year ontogenetic diet patterns in two coexisting Sander species, S. lucioperca and S. volgensis in Lake Balaton. Hydrobiologia 549: 115-130.

Specziar, A., M. Bercsenyi \& T. Muller, 2009. Morphological characteristics of hybrid pikeperch (Sander lucioperca female $\times$ Sander volgensis male) (Osteichthyes, Percidae). Acta Zoologica 55: 39-54.

Spindler, T., 1997. Fischfauna in Österreich, Vol. 87. Bundesministerium für Umwelt, Jugend und Familie, Vienna.

Urho, L., 1996. Identification of perch (Perca fluviatilis), pikeperch (Stizostedion lucioperca) and ruffe (Gymnocephalus cernuus) larvae. Annales Zoologici Fennici 33: $659-667$.

via donau, 2012. Die kennzeichnenden Wasserstände der österreichischen Donau. via donau - Österreichische Wasserstraßen-Gesellschaft mbH, Vienna.

Wiesner, C., 2005. New records of non-indigenous gobies (Neogobius spp.) in the Austrian Danube. Journal of Applied Ichthyology 21: 324-327.

Wiesner, C., C. Wolter, W. Rabitsch \& S. Nehring, 2010. Gebietsfremde Fische in Deutschland und Österreich und mögliche Auswirkungen des Klimawandels. BfN-Skripten 279: 1-196.

Wintersberger, H., 1996. Spatial resource utilization and species assemblages of larval and juvenile fishes. Large Rivers 11: 29-44.

Wolfram, G. \& E. Mikschi, 2007. Rote Liste der Fische (Pisces) Österreichs. In Zulka, K. P. (ed), Rote Listen gefährdeter Tiere Österreichs Checklisten, Gefährdungsanalysen, Handlungsbedarf, Vol. 2., Grüne Reihe des Bundesministeriums für Land- und Forstwirtschaft Umwelt und Wasserwirtschaft, Vienna: 61-198.

Wolter, C. \& A. Sukhodolov, 2008. Random displacement versus habitat choice of fish larvae in rivers. River Research and Applications 24: 661-672.

Zauner, G. \& J. Eberstaller, 1999. Klassifizierungsschema der österreichischen Flußfischfauna in bezug auf deren Lebensraumansprüche. Österreichs Fischerei 52: 198-205.

Zitek, A., S. Schmutz \& A. Ploner, 2004a. Fish drift in a Danube sidearm-system: II. Seasonal and diurnal patterns. Journal of Fish Biology 65: 1339-1357.

Zitek, A., S. Schmutz, G. Unfer \& A. Ploner, 2004b. Fish drift in a Danube sidearm-system: I. Site-, inter- and intraspecific patterns. Journal of Fish Biology 65: 1319-1338. 